\title{
ANALISIS TINGKAT KEPUASAN PENGGUNA SISTEM INFORMASI UJIAN AKHIR SEMESTER (SIUAS) MENGGUNAKAN METODE SERVICE QUALITY (SERVQUAL)
}

\author{
Nanny Raras Setyoningrum ${ }^{1}$, Prihandoko ${ }^{2}$ \\ ${ }^{1}$ Magister Teknik Informatika Universitas AMIKOM Yogyakarta Indonesia \\ 1ra2s_ukhti@yahoo.co.id \\ ${ }^{2}$ Fakultas Ilmu Komputer dan Teknologi Informasi Universitas Gunadarma \\ 2pri@staff.gunadarma.ac.id.
}

\begin{abstract}
Intisari- Penelitian ini berkaitan dengan tingkat kepuasan sistem informasi ujian akhir semester pada STTI Tanjungpinang dengan menggunakan pendekatan metode ServQual. Hal ini dilakukan karena belum pernah dilakukan pengukuran tingkat kepuasan pengguna sistem pada STTI Tanjungpinang. Adapun tujuan dari penelitian ini adalah untuk mengetahui persentase tingkat kepuasan pengguna sistem yang diukur dengan pendekatan metode Servqual. Penelitian ini dilakukan dengan cara menyebarkan kuesioner kepada responden pengguna aplikasi, yang sebelumnya dilakukan wawancara kepada pengguna sistem. Pemilihan responden dilakukan menggunakan teknik purposive sampling sebab hanya responden yang menggunakan aplikasi saja yang dipilih. Analisis dilakukan dengan menghitung persentase tingkat kepuasan pengguna dengan pendekatan ServQual. Hasil penelitian ini menunjukan bahwa Hasil analisis tingkat kepuasan pengguna SIUAS menggunakan metode ServQual menghasilkan tingkat kepuasan yang dirasakan pengguna sebesar $\mathbf{8 4 , 1 2 \%}$ dengan gap/selisish sebesar $15,88 \%$ artinya pengguna berada pada rentang kategori sangat puas dimana dari kelima dimensi tersebut variable tangible memiliki gap/selisih terkecil yaitu $12,74 \%$ sedangkan gap/selisih terbesar ada pada variable reliability, yaitu sebesar $18,06 \%$. Kesimpulan penelitian ini adalah bahwa persentase kepuasan pengguna dengan metode ServQual berada pada range kategori puas. Berdasarkan dimensi perbaikan maka dimensi pada metode ServQual terdapat tiga item perbaikan yaitu dua pada dimensi reliability dan satu pada dimensi responsiveness. Rekomendasi perbaikan masih diperlukan supaya menghasilkan perangkat lunak yang baik. Berdasarkan dimensi perbaikan maka analisis menggunakan metode ServQual terdapat tiga perbaikan yaitu dimensi reliability pada bagian loading saat mengakses sistem dan detail penelusuran aktivitas pengguna serta dimensi responsiveness pada bagian menanggapi terjadinya trouble.
\end{abstract}

Kata kunci: analisis tingkat kepuasan, website, ServQual

Abstract- The research was about the satisfaction level of the semester test information system at STTI Tanjungpinang by using the ServQual method. This is done because there has never been a measurement of the level of system user satisfaction on the STTI Tanjungpinang. The purpose of this research was to determine the percentage of system user satisfaction levels measured by the Servqual method. This research was conducted by distributing questionnaires to the respondents of application users, who were previously interviewed to system users. The selection of respondents was conducted using purposive sampling technique because only respondents who used the application were selected. The questionnaire distributed consists of the ServQual method. The analysis was carried out by calculating the percentage of user satisfaction with the ServQual approaches. The results of this study indicate that the results of the analysis of the level of satisfaction of SIUAS users using the ServQual method produces user perceived satisfaction level of $84.12 \%$ with gap / difference of $\mathbf{1 5 . 8 8 \%}$ meaning that the user is in a very satisfied category range where from these five dimensions the tangible variable has the smallest gap / $12.74 \%$ while the biggest gap is in the reliability variable, which is $18.06 \%$. The conclusion of this study is the ServQual method there are three improvement items, namely two on the reliability dimension and one on the responsiveness dimension. Repair recommendations are still needed to produce good software. Based on the improvement dimensions, the analysis uses the ServQual method there are three improvements namely reliability dimensions in the loading section when accessing the system and details of user activity tracking and dimensions of responsiveness on the part of the trouble response.

Keywords: satisfaction level analysis, website, ServQual 


\section{Pendahuluan}

Perkembangan teknologi yang cukup pesat telah membawa pada peradaban baru, lembaga atau perusahaan berlomba-lomba meningkatkan pelayanan dengan memanfaatkan teknologi informasi. Pemanfaatan teknologi informasi cenderung diidentikkan kepada perumusan pekerjaan yang lebih cepat, akurat, efektif dan efisien baik dari segi waktu maupun biaya. Pemanfaatan teknologi informasi dalam dunia pendidikan telah banyak berkembang khususnya pada perguruan tinggi. Sebagai contoh penerapan teknologi informasi tingkat perguruan tinggi adalah penyampaian informasi disajikan melalui website resmi Perguruan Tinggi tersebut.

Sekolah Tinggi Teknologi Indonesia Tanjungpinang merupakan salah satu Perguruan Tinggi yang menggunakan sistem terintegrasi dengan teknologi informasi. Salah satu sistem berbasis web yang dimiliki oleh Sekolah Tinggi Teknologi Indonesia Tanjungpinang adalah sistem informasi ujian akhir semester. Dengan teknologi ini, ujian akhir semester tidak lagi menggunakan metode manual dengan lembar jawaban tetapi mahasiwa dapat menjawab langsung pada komputer atau laptop.

Dalam konsep SIUAS, adanya integrasi dengan sistem informasi akademik maka memudahkan panitia dalam verifikasi peserta ujian. Selain itu juga memberikan kemudahan bagi panitia ujian di mana panitia ujian tidak perlu lagi mencetak soal dan menggandakannya tetapi dosen pengampu cukup mengunggah soal dalam format word, atau picture (.jpeg) ke dalam sistem. Mahasiswa juga lebih mudah dalam menjawab soal hanya dengan mengetikkan jawaban pada kolom jawaban yang telah disediakan lalu save dan submit maka otomatis jawaban akan tersimpan dalam database.

\subsection{Analisis Tingkat Kepuasan Pengguna}

Analisis tingkat kepuasan ini penting untuk mengetahui sejauh mana harapan dan kenyataan dari pengguna sistem dalam upaya mencapai kesempurnaan sebuah sistem informasi. Analisis tingkat kepuasan pengguna terhadap perangkat lunak sangat diperlukan agar dapat memenuhi harapan pengguna. Kebutuhan akan kualitas perangkat lunak yang baik sangat diinginkan baik oleh manajemen, pengelola perangkat lunak hingga pengguna akhir. Hal ini disebabkan karena kualitas perangkat lunak yang baik dapat berdampak pada peningkatan kepuasan pengguna akhir.

Terdapat beberapa cara untuk menganalisis tingkat kepuasan pengguna terhadap sistem informasi, salah satunya dengan menggunakan metode Service Quality. Kepuasan pengguna merupakan salah satu indikator dari keberhasilan pengembangan sistem informasi. Sistem informasi dapat diandalkan apabila memiliki kualitas yang baik dan mampu memberikan kepuasan pada pemakainya.

\subsection{Metode Service Quality (servqual)}

Konsep dasar kepuasan pengguna adalah tingkat harapan dan layanan yang diberikan kepada pengguna. Menurut Pasaruraman, konsep dasar ServQual adalah (Sambodo; 2014) :

\section{Perceived quality vs objective quality}

Konsumen dan peneliti memiliki pemahaman berbeda tentang kualitas. Peneliti mendefinisikan kualitas secara konseptual. Konseptual artinya adalah membedakan antara kualitas mekanis dan kualitas sumber daya manusia. Kualitas mekanis meliputi aspek objektif suatu proses, sedangkan kualitas sumber daya manusia meliputi bagaimana respon subjektif terhadap suatu proses.

2. Quality as attitude

Kualitas dilihat sebagai bentuk evaluasi keseluruhan suatu produk.

3. Quality versus satisfaction

Kepuasan adalah suatu titik simpulan psikologis mengenai perasaan konsumen terhadap pengalaman yang diterimanya dan harapan mereka.

4. Expectation compared to perceptions

Kualitas pelayanan berakar dari perbandingan antara pelayanan yang seharusnya diberikan kepada konsumen dan persepsi konsumen terhadap performa pelayanan.

Terdapat 5 dimensi pada model ServQual berdasarkan tingkat kepentingan relatifnya, seperti pada Tabel 1.

Tabel 1

Dimensi ServQual

\begin{tabular}{|c|c|}
\hline Dimensi & Indikator \\
\hline $\begin{array}{l}\text { Tangibles } \\
\text { (dapat dihitung) }\end{array}$ & $\begin{array}{ll}\text { a. } & \text { Lingkungan fisik } \\
\text { b. } & \text { Fasilitas } \\
\text { c. } & \text { Penampilan sistem } \\
\text { d. } & \text { Komunikasi } \\
\text { e. } & \text { Daya tarik system } \\
\end{array}$ \\
\hline Reliability & $\begin{array}{l}\text { a. Pelayanan tepat waktu } \\
\text { a. Pelayanan tanpa kesalahan }\end{array}$ \\
\hline Responsiveness & $\begin{array}{l}\text { a. Kemampuan support pengguna } \\
\text { b. Respon yang cepat dan tepat } \\
\text { c. Tanggap terhadap permintaan } \\
\text { pengguna }\end{array}$ \\
\hline Assurance & $\begin{array}{ll}\text { a. } & \text { Perilaku karyawan } \\
\text { b. } & \text { Kepercayaan pengguna }\end{array}$ \\
\hline Emphaty & $\begin{array}{l}\text { a. Kepedulian terhadap pengguna } \\
\text { b. Jam operasional yang siap siaga }\end{array}$ \\
\hline
\end{tabular}

\subsection{Sistem Informasi Ujian Akhir Semester (SIUAS)}

Sistem Ujian Akhir Semester (SIUAS) merupakan salah satu software berbasis web yang digunakan oleh Sekolah Tinggi Teknologi Indonesia Tanjungpinang pada pelaksanaan ujian akhir semester secara paperless atau online menggunakan notebook atau laptop yang dapat diakses melalui web browser. 
Adapun struktur organisasi Sekolah Tinggi Teknologi Indonesia Tanjungpinang yang terkait dengan SIUAS seperti terlihat pada gambar 1 .

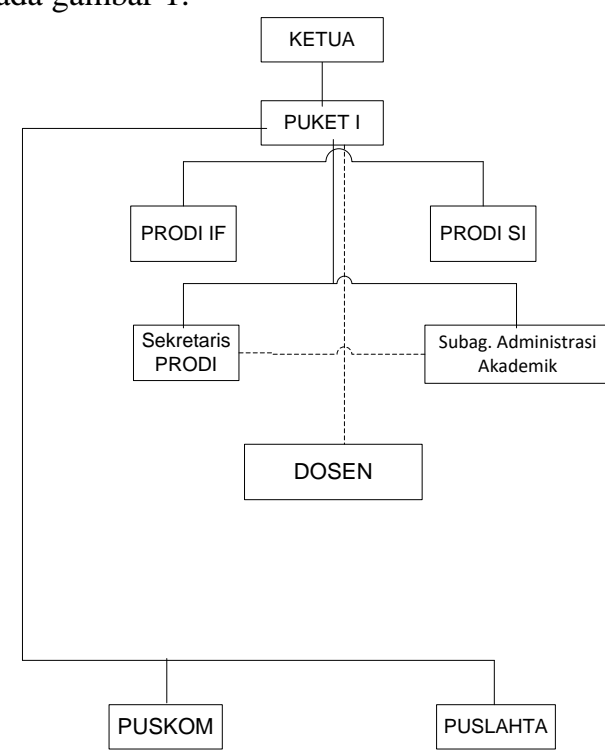

Gambar 1. Struktur manajemen pengguna SIUAS

Bagian dari manajemen institusi yang menjadi pengguna SIUAS, diantaranya :

1. Admin, yang bertindak sebagai admin adalah bagian puskom dengan tugas membuat sistem dan bertanggung jawab penuh terhadap DBMS sistem.

2. Panitia UAS, yang bertindak sebagai panitia UAS adalah bagian akademik, prodi dan puslahta dengan tugas menginputkan data-data terkait UAS misalnya data tata tertib ujian, data mahasiwa, data dosen, data jadwal ujian dan lain-lain.

3. Dosen, bertugas menginputkan soal UAS dan memeriksa jawaban mahasiswa melalui SIUAS serta ada yang bertugas sebagai pengawas UAS.

4. Mahasiswa, pada saat ujian mahasiswa login ke SIUAS, sistem akan memvalidasi KRS mahasiswa, lalu mahasiswa menjawab soal ujian pada SIUAS selanjutnya sistem akan melakukan validasi batas waktu ujian.

Tampilan halaman muka dari SIUAS masih sederhana, beberapa fitur pada SIUAS sebagai berikut :

1. Halaman menu utama

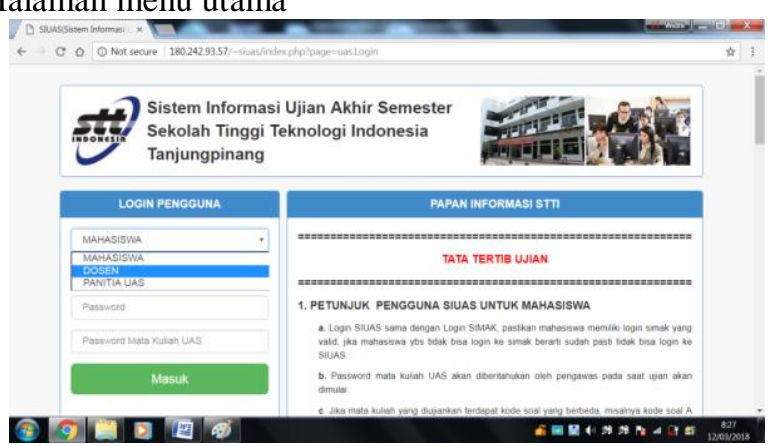

Gambar 2 Halaman menu utama SIUAS
Pada halaman menu utama ini terdapat fitur login yang terdiri atas mahasiswa, dosen dan panitia UAS. Selain itu juga memuat papan informasi yang berisi tata tertib ujian.

2. Halaman login sebagai dosen

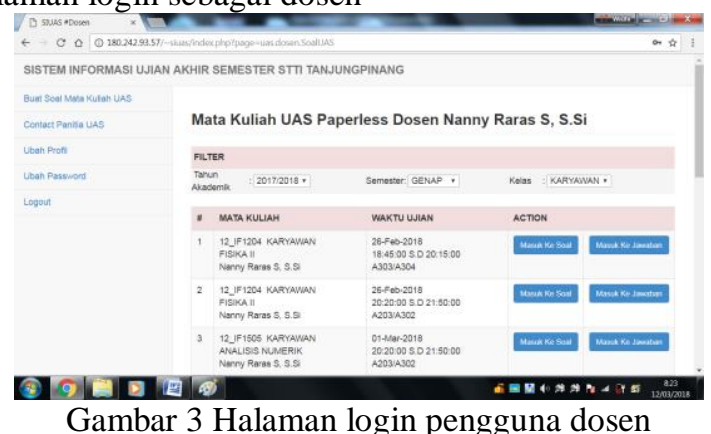

Pada halaman ini dosen memiliki menu untuk membuat soal, mengubah profil, mengubah password dan logout.

3. Halaman dosen membuat soal

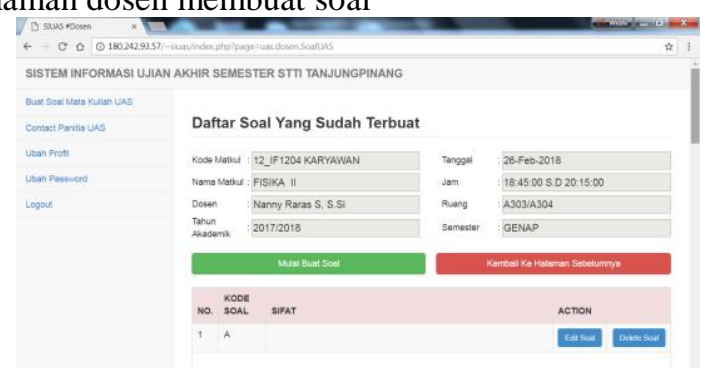

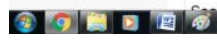

Gambar 4 Halaman upload soal

Pada halaman ini dosen dapat mengupload soal sesuai dengan jadwal yang sebelumnya telah diinput oleh panitia ujian.

Flowmap dari Sistem Ujian Akhir Semester (SIUAS) yang berjalan adalah seperti terlihat pada gambar 5 


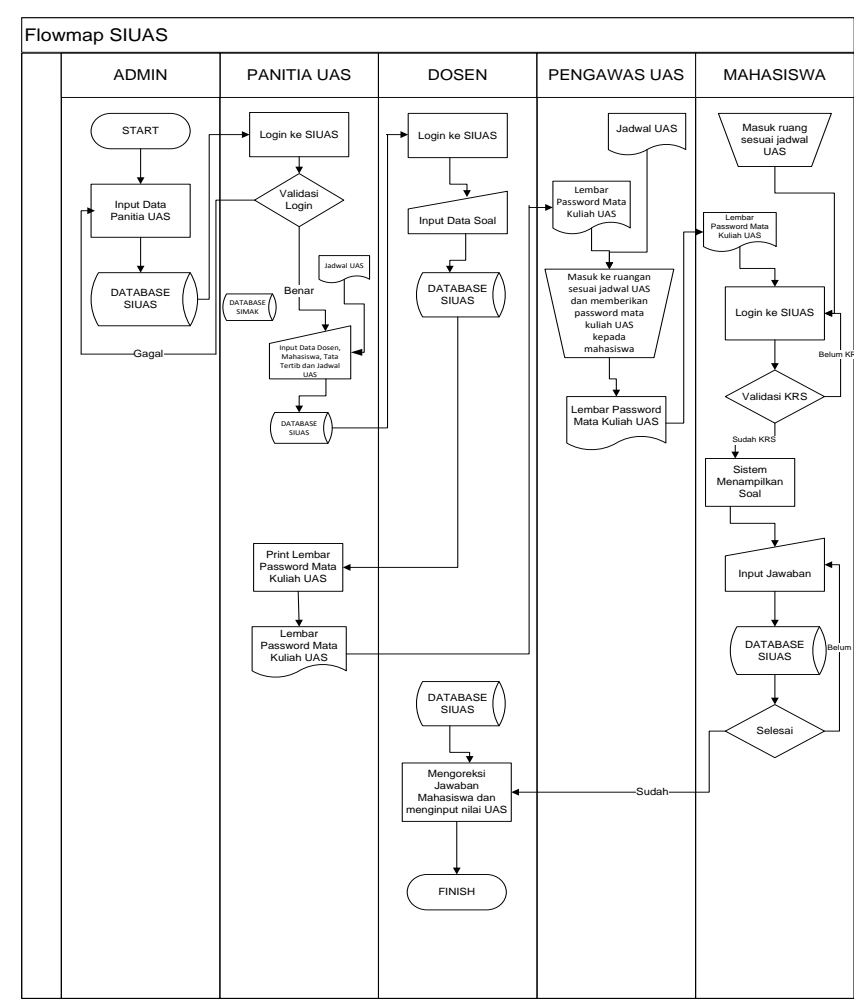

Gambar 5. Flowmap SIUAS.

\subsection{Penelitian Terkait}

Metode untuk analisis tingkat kepuasan pengguna perangkat lunak adalah metode Service Quality (ServQual). Seperti penelitian yang dilakukan oleh Sabina dan Samira (2015) dengan judul penelitian "Quality Assessment in Higher Education Using The ServQual Model". Tujuan dari penelitian itu adalah memberikan bukti empiris bahwa model ServQual dapat digunakan untuk mengidentifikasi kesenjangan kualitas layanan pada salah satu institusi pendidikan tinggi. Hasil dari penelitian menunjukkan bahwa dengan metode ServQual dapat menilai kualitas layanan pada pendidikan tinggi dan menunjukkan adanya gap negative antara harapan mahasiswa dan persepsi institusi pendidikan tinggi. Karenanya perlu adanya peningkatan pada semua segment agar kualitas layanan pada pendidikan tinggi semakin baik.

Penelitian metode ServQual juga dilakukan oleh Sambodo dan Dirgantara (2014), dengan studi kasus pada media sosial Bhinneka.com, PT. Bhinneka Mentari Dimensi yang merupakan salah satu perusahaan bisnis online yang melakukan promosi dan transaksi melalui media sosial dan web. Pada penelitian ini dibahas tentang kepuasan konsumen PT. Bhinneka Mentari Dimensi dengan peranan media sosial. Kepuasan konsumen ditentukan dengan menghitung selisih antara nilai kenyataan yang diterima konsumen dan nilai harapan konsumen. Media sosial yang digunakan antara lain adalah facebook, twitter, website Bhinneka.com, dan media soaial lainnya. Dari perhitungan tingkat kepuasan konsumen dengan dimensi ServQual dan analisis GAP maka akan dihasilkan suatu strategi untuk mempertahankan atau meningkatkan kepuasan konsumen.

Penulis melakukan penelitian analisis tingkat kepuasan pengguna menggunakan metode servqual dengan harapan mendapatkan hasil analisis terbaik dan dapat memberikan saran yang lebih baik dan lengkap berdasarkan temuan yang dirasa masih kurang terhadap peningkatan kualitas perangkat lunak yaitu sistem informasi ujian akhir semester berbasis web.

\section{Metodologi Penelitian}

Jenis penelitian ini ialah penelitian deskriptif. Penelitian deskriptif yaitu penelitian yang dimaksudkan untuk menggambarkan fenomena-fenomena yang ada, yang berlangsung pada saat ini atau saat yang lampau.

\section{a. Teknik Pengumpulan Data}

Teknik pengumpulan data dengan cara observasi, wawancara dan kuesioner. Wawancara dilakukan dengan beberapa pengguna sistem terkait persepsi dan harapan pengguna. Untuk mendapatkan data primer, pada penelitian ini juga melakukan penyebaran kuesioner terhadap responden.

\section{b. Sampel Penelitian}

Objek dari penelitian ini yaitu para pengguna SIUAS yang terdiri dari manajemen, staff Puskom dan Puslahta sebagai admin, dosen dan mahasiswa dengan responden sebanyak 47 orang dengan teknik pengambilan sampel yang digunakan adalah purposive random sampling.

\section{c. Skala Pengukuran}

Sebelum melakukan penyebaran kuesioner ditentukan terlebih dahulu kriteria penilaian sebagai dasar pengukuran kuesioner yaitu dengan skala Likert. Berikut ini merupakan pembagian kriteria penilaian pada penelitian ini :

Tabel 2

Kriteria penilaian

\begin{tabular}{|l|l|l|l|}
\hline No & Simbol & Kriteria penilaian & Skor \\
\hline 1 & SS & Sangat Setuju/Sangat Puas & 5 \\
\hline 2 & S & Setuju / Puas & 4 \\
\hline 3 & CS & Cukup Setuju/Cukup Puas & 3 \\
\hline 4 & TS & Tidak Setuju / Tidak Puas & 2 \\
\hline 5 & STS & $\begin{array}{l}\text { Sangat Tidak Setuju/ Sangat } \\
\text { Tidak Puas }\end{array}$ & 1 \\
\hline
\end{tabular}

Sumber : Riduwan (2009)

\section{d. Pengolahan Data Kuesioner}

Data kuesioner selanjutnya akan diolah untuk memperoleh hasil dari analisis tingkat kepuasan pengguna terhadap Sistem Informasi Ujian Akhir Semester menurut persepsi dan harapan pengguna. Sesuai penjelasan pada analisis tingkat kepuasan responden bahwa interval persentase tingkat kepuasan pengguna diinterpretasikan sebagai berikut : 
Tabel 3.

Interpretasi persentase tingkat kepuasan pengguna

\begin{tabular}{|l|l|}
\hline Interval & Kriteria \\
\hline $81 \%-100 \%$ & Sangat Puas \\
\hline $61 \%-80 \%$ & Puas \\
\hline $41 \%-60 \%$ & Cukup Puas \\
\hline $21 \%-40 \%$ & Tidak Puas \\
\hline $0 \%-20 \%$ & Sangat Tidak Puas \\
\hline
\end{tabular}

\section{HASIL DAN PEMBAHASAN}

Berdasarkan rekapitulasi kuesioner dengan pendekatan metode ServQual yang telah dilakukan sebelumnya, maka diperoleh skor criteria (skor ideal), total skor pengumpulan data variable dan besarnya persentase masing - masing variable penilaian kuesioner metode ServQual. Adapun langkah - langkah pada masing - masing dimensi sebagai berikut :

1. Menentukan skor criteria (skor ideal)

a. Tangible

Pada dimensi tangible terdapat 2 item pertanyaan dimana masing - masing pertanyaan memiliki skor maksimal 5 dengan jumlah responden sebanyak 47 orang, sehingga diperolah skor criteria (skor ideal) sebagai berikut :

$$
\sum S K=5 \times 2 \times 47=470
$$

Dari perhitungan diatas maka didapatkan range kategorinya, adapun range kategorinya adalah sebagai berikut

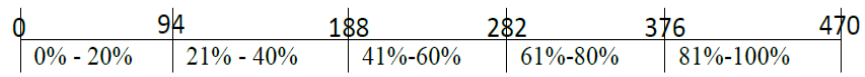

\section{b. Reliability}

Pada dimensi reliability terdapat 5 item pertanyaan dimana masing - masing pertanyaan memiliki skor maksimal 5 dengan jumlah responden sebanyak 47 orang, sehingga diperolah skor criteria (skor ideal) sebagai berikut :

$$
\sum S K=5 \times 5 \times 47=1175
$$

Dari perhitungan diatas maka didapatkan range kategorinya, adapun range kategorinya adalah sebagai berikut

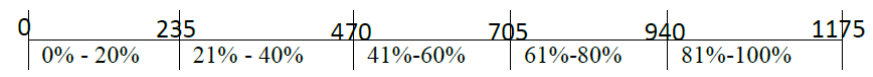

c. Responsiveness

Pada dimensi responsiveness terdapat 3 item pertanyaan dimana masing - masing pertanyaan memiliki skor maksimal 5 dengan jumlah responden sebanyak 47 orang, sehingga diperolah skor criteria (skor ideal) sebagai berikut :

$$
\sum S K=5 \times 3 \times 47=705
$$

Dari perhitungan diatas maka didapatkan range kategorinya, adapun range kategorinya adalah sebagai berikut

\begin{tabular}{|l|l|l|l|l|}
\multicolumn{1}{|c|}{141} & 282 & 423 & 564 & 705 \\
\hline $0 \%-20 \%$ & $21 \%-40 \%$ & $41 \%-60 \%$ & $61 \%-80 \%$ & $81 \%-100 \%$
\end{tabular}

\section{d. Assurance}

Pada dimensi assurance terdapat 3 item pertanyaan dimana masing - masing pertanyaan memiliki skor maksimal 5 dengan jumlah responden sebanyak 47 orang, sehingga diperolah skor criteria (skor ideal) sebagai berikut :

$$
\sum S K=5 \times 3 \times 47=705
$$

Dari perhitungan diatas maka didapatkan range kategorinya, adapun range kategorinya adalah sebagai berikut

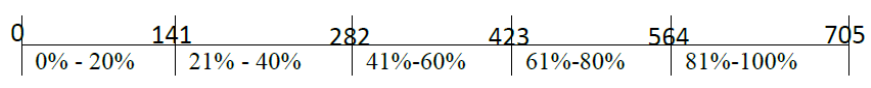

e. Emphaty

Pada dimensi emphaty terdapat 6 item pertanyaan dimana masing - masing pertanyaan memiliki skor maksimal 5 dengan jumlah responden sebanyak 47 orang, sehingga diperolah skor criteria (skor ideal) sebagai berikut :

$$
\sum S K=5 \times 6 \times 47=1410
$$

Dari perhitungan diatas maka didapatkan range kategorinya, adapun range kategorinya adalah sebagai berikut

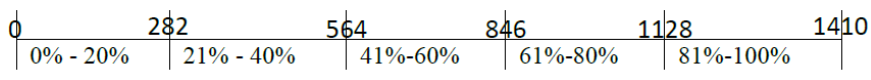

2. Menentukan jumlah total skor pengumpulan data variable.

Berdasarkan rekapitulasi skor item pertanyaan sesuai pendekatan metode ServQual maka jumlah total skor pengumpulan data masing-masing dimensi disajikan dalam tabel berikut :

Tabel 4.

Jumlah total skor pengumpulan data variable metode Service Quality (ServQual)

\begin{tabular}{|l|l|l|}
\hline \multirow{2}{*}{ Dimensi } & \multicolumn{2}{|c|}{ Skor Total } \\
\cline { 2 - 3 } & $\begin{array}{l}\text { Persepsi } \\
\text { Pengguna }\end{array}$ & $\begin{array}{l}\text { Harapan } \\
\text { Pengguna }\end{array}$ \\
\hline Tangible & 363 & 416 \\
\hline
\end{tabular}




\begin{tabular}{|l|l|l|}
\hline Reliability & 835 & 1019 \\
\hline Responsiveness & 514 & 614 \\
\hline Assurance & 513 & 624 \\
\hline Emphaty & 1075 & 1250 \\
\hline
\end{tabular}

\begin{tabular}{|l|c|c|c|c|}
\hline Reliability & 835 & 1019 & $81,94 \%$ & $\begin{array}{c}18,06 \\
\%\end{array}$ \\
\hline $\begin{array}{l}\text { Responsiv } \\
\text { eness }\end{array}$ & 514 & 614 & $83,71 \%$ & $\begin{array}{c}16,29 \\
\%\end{array}$ \\
\hline Assurance & 513 & 624 & $82,21 \%$ & $\begin{array}{c}17,79 \\
\%\end{array}$ \\
\hline Emphaty & 1075 & 1250 & $86,00 \%$ & $\begin{array}{c}14,00 \\
\%\end{array}$ \\
\hline Total & $\mathbf{3 3 0 0}$ & $\mathbf{3 9 2 3}$ & $\mathbf{8 4 , 1 2 \%}$ & $\begin{array}{c}\mathbf{1 5 , 8 8} \\
\mathbf{\%}\end{array}$ \\
\hline
\end{tabular}

3. Menentukan besarnya persentase masing - masing dimensi

Berdasarkan jumlah total skor pengumpulan data variable selanjutnya menentukan besarnya persentase tingkat kepuasan pengguna dengan membandingkan antara persepsi dan harapan pengguna SIUAS yang disajikan dalam tabel berikut :

Tabel 5.

Persentase tingkat kepuasan pengguna dengan metode ServQual

\begin{tabular}{|l|l|l|l|}
\hline \multirow{2}{*}{ Dimensi } & \multicolumn{2}{|c|}{ Skor Total } & Tingkat \\
& Kepuasan \\
& $\begin{array}{l}\text { Persepsi } \\
\text { Pengguna }\end{array}$ & $\begin{array}{l}\text { Harapan } \\
\text { Pengguna }\end{array}$ \\
\hline Tangible & 363 & 416 & $87,26 \%$ \\
\hline Reliability & 835 & 1019 & $81,94 \%$ \\
\hline Responsiveness & 514 & 614 & $83,71 \%$ \\
\hline Assurance & 513 & 624 & $82,21 \%$ \\
\hline Emphaty & 1075 & 1250 & $86,00 \%$ \\
\hline
\end{tabular}

\section{Hasil Analisis}

Hasil analisis tingkat kepuasan responden terhadap kinerja dan harapan dari masing-masing variabel di atas dapat diolah lebih lanjut untuk mendapatkan nilai gap/selisih pada masing-masing dimensi. Hal ini dilakukan agar dapat dilakukan evaluasi terhadap SIUAS. Nilai gap/selisih masingmasing dimensi disajikan dalam tabel berikut :

Tabel 6.

Nilai gap/selisih masing-masing dimensi pada metode ServQual

\begin{tabular}{|c|c|c|c|c|}
\hline \multirow{2}{*}{ Dimensi } & \multicolumn{2}{|c|}{ Skor Total } & \multirow{2}{*}{$\begin{array}{l}\text { Tingkat } \\
\text { Kepuas } \\
\text { an (\%) }\end{array}$} & \multirow{2}{*}{$\begin{array}{c}\text { GAP/ } \\
\text { Selisih } \\
(\%)\end{array}$} \\
\hline & $\begin{array}{c}\text { Persepsi } \\
\text { Pengguna }\end{array}$ & $\begin{array}{l}\text { Harapan } \\
\text { Pengguna }\end{array}$ & & \\
\hline Tangible & 363 & 416 & $87,26 \%$ & $\begin{array}{c}12,74 \\
\%\end{array}$ \\
\hline
\end{tabular}

Berdasarkan tabel 6, total tingkat kepuasan yang dirasakan pengguna SIUAS menggunakan pendekatan metode ServQual sebesar $84,12 \%$ dengan gap/selisish sebesar $15,88 \%$ artinya pengguna berada pada rentang kategori sangat puas. Dari kelima dimensi tersebut variable tangible memiliki gap/selisih terkecil yaitu $12,74 \%$ sedangkan gap/selisih terbesar ada pada variable reliability, yaitu sebesar 18,06,\% .

\section{KESIMPULAN}

\subsection{Kesimpulan}

Berdasarkan pembahasan dan hasil analisis data, maka diperoleh kesimpulan sebagai berikut :

1. Hasil analisis tingkat kepuasan pengguna Sistem Informasi Ujian Akhir Semester Sekolah Tinggi Teknologi Indonesia Tanjungpinang menggunakan metode Service Quality menghasilkan tingkat kepuasan yang dirasakan pengguna sebesar $84,12 \%$ dengan gap/selisish sebesar $15,88 \%$ artinya pengguna berada pada rentang kategori sangat puas.

2. Dari kelima dimensi tersebut variable tangible memiliki gap/selisih terkecil yaitu 12,74\% sedangkan gap/selisih terbesar ada pada variable reliability, yaitu sebesar $18,06, \%$.

\subsection{Saran}

Berdasarkan hasil penelitian diatas, maka dapat di buat beberapa saran berikut :

1. Pada penelitian ini hanya menggunakan satu metode analisis tingkat kepuasan pengguna yaitu metode Service Quality, alangkah baiknya jika penelitian - penelitian selanjutnya dilakukan komparasi dari dua atau lebih metode.

2. Penilaian perangkat lunak pada penelitian ini sebatas pada persepsi pengguna saja. Alangkah lebih baik apabila penilaian terhadap perangkat lunak bukan hanya menurut persepsi pengguna saja tetapi berdasarkan produk dari perangkat lunak itu sendiri.

\section{REFERENSI}

[1] Donlagic, Sabina dan Samira Fazlic, 2015, Quality Assessment in Higher Education Using The Servqual Model, Management, Vol.20, pp. 39-57

[2] Hidayat, Rahmat, 2010, Cara praktis Membangun Website Gratis, PT. Elex Media Komputindo, Jakarta 
Bangkit Indonesia, Vol. VII, No.2, Oktober 2018

[3] Jessi, 2015, Analisa Kepuasan Pelanggan Terhadap Kualitas Pelayanan Restoran Dengan Menggunakan metode Servqual dan Quality Function Deployment (QFD), Paradigma, Vol.XVII, September 2015

[4] Pressman, Roger, 2002, Rekayasa Perangkat Lunak Pendekatan Praktisi (Buku Satu), Andi, Yogyakarta

[5] Rachmanto, Ricky, 2015, Website Iklan Baris dengan Wordpress, PT. Elex Media Komputindo, Jakarta

[6] Sambodo, Aryo Tri dan Dirgantara, Harya Bima., 2014, Analisis Kepuasan Konsumen Dengan Servqual Studi Kasus : Media Sosial Bhinneka.com, Seminar Nasional Sistem Informasi Indonesia, September 2014

[7] Sommerville, Ian., 2011, Software Engineering, Pearson, Massachusetts

[8] Sulianta, Feri, 2008, Komputer Forensik, PT.Elex Media Komputindo, Jakarta

[9] Suyanto, M., 2005, Pengantar Teknologi Informasi Untuk Bisnis, Andi, Yogyakarta

[10] Zhang, Songtao dan Yanting Hou, 2013, Measuring Service Quality of Supply Chain with Servqual, Information Technology Journal, ISSN 1812-5638 